\title{
Virtual or Real: Discussion on Application of Semi-Virtual Exhibition Space
}

\author{
Yi Wang* \\ Creative Centre for Art-Science-Architecture, Jilin Jianzhu University, Changchun, 130118, China
}

\begin{abstract}
The extensive application of digital technology and the development of technology have brought new opportunities for traditional exhibition space design. In the past, particular places were displayed mostly through text, display board, video and device, etc. The traditional exhibition way has very important significance for cultural dissemination but has shortcomings in preparation space experience restoration. The application of new technology can help the exhibition space design present in a new way. The author defines this method as the semi-virtual exhibition space, and in the construction of this space, the virtual display medium is arranged according to the space position of reality. The content of space-time change and site behavior change is aided by the designed script. This kind of exhibition space construction has raised higher requests to the designer, regardless of the designer's own knowledge structure, and adapts the new technology innovation. Both need to adapt to the challenges brought about by this development. This paper expounds this new concept and discusses how to construct a new knowledge system.
\end{abstract}

Keywords: semi-virtual exhibition space; virtual space; virtual reality; exhibition space; communication

(Submitted on November 15, 2018; Revised on December 13, 2018; Accepted on January 12, 2019)

(C) 2019 Totem Publisher, Inc. All rights reserved.

\section{Introduction}

The application of new technologies provides more expression method for traditional exhibition space settings. As an important means of cultural communication, the exhibition space's design and use have encountered more opportunities in modern times than ever before. New technologies, which can better make up for the lack of experience restoration of the exhibited space in traditional exhibition, are constantly being invented. The traditional exhibition space design has more methods to restore and create large-scale space with the help of new technologies. How to apply multiple technologies has brought new challenges to designers. The author defines this method as a semi-virtual exhibition space. In the creation of this space, the virtual display medium is placed with reference to the spatial position of the reality and is assisted by the content of the space-time change and the place behavior change according to the designed script. In this paper, the author will elaborate this new exhibition method and how to better integrate multiple technologies.

\section{The Concept of Semi-Virtual Space}

The technological base for realizing semi-virtual space is a combination of visual information communication that is composed of multiple sets of multi-directionally continuous pictures in frame units and coordination of simulated sound effects of different spatial levels, along with the assistance of other sensory information such as tactile sense and sense of taste.

This is similar to the infinite loop image produced by two mirrors placed on opposite sides (Figure 1). Though this mirror image is placed on the same plane as the non-mirror wall next to it, it gives the viewer a very far-reaching space experience. The visual realization of the semi-virtual space is based on different shapes of the playing media placed in the display space, which can be LCD screens, projections, LED displays, lights, etc., according to the characteristics of the restored scene. Due to the different locations of the various media in the exhibition space, visitors need to follow the tour route. By integrating the visual experience of different visit points, the viewer will experience the effect of the designer's

\footnotetext{
* Corresponding author.

E-mail address: $57593701 @ \mathrm{qq} . c 0 m$
} 
comprehensive design.

The interactive device and the behavior capture device will be adjusted according to the change of the visitor's location. At the same time, sound, touch sense (the ground of different texture, walls, objects, water mist, etc.), temperature changes, wind, and other image factors together constitute the visitors' perception of the whole visit.

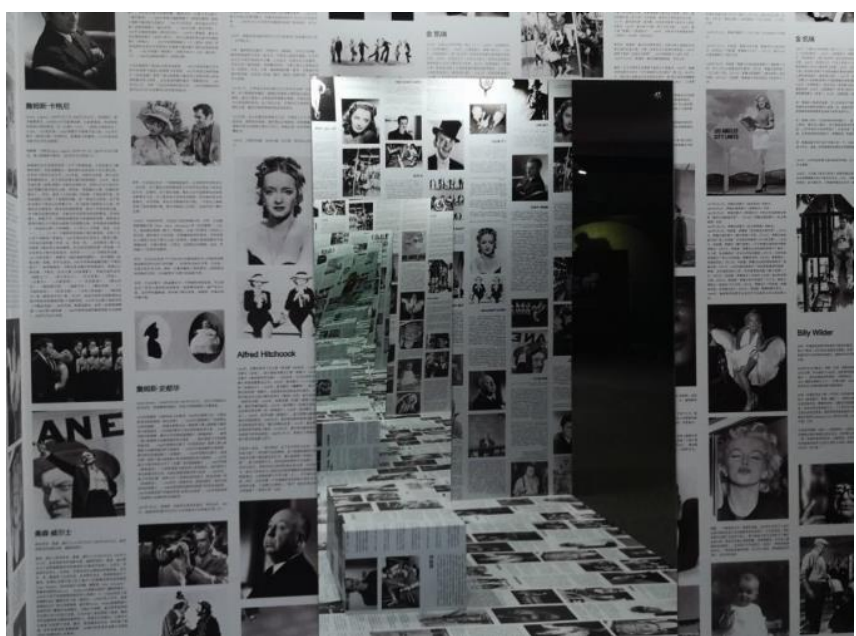

Figure 1. Being virtual or real: a discussion on the application of the semi-virtual exhibition space

\section{Virtual Space Simulating Realistic Cognition Environment}

The cognitive accumulation based on experience constitutes human understanding of the outside world. The media and processes of accumulation can now be simulated through computer-based techniques. The process of human cognition includes vision, auditory sense, and tactile sense. If the communication of these information can be fully simulated, it will be the creation of differently new spaces.

The feeling of being immersive is the eternal pursuit of communication. From the earliest ancient scrawl to the long poems passed on from mouth to mouth, from the words on the walls of objects to paper and books, from silent films to VR and AR, the advancement of technology has brought more expressions of communication, following the eternal theme. The feeling of being on the scene has constantly been strengthened, and the output of information has also developed from a single element to holographic expression. The sense of presence created by the piling up of words has been extended to a holographic expression that gives the viewer a stronger sense of presence.

When "Water Lilies" was exhibited, the French art world was shocked by the innovative topic, the bold cutting of the composition, the blending of light and color, and the wild and vivid techniques. There were greenness, ripples, red lotus, sky and water without beginning or end, and people were immediately surrounded by a green, blue, and charming illusion world. The situation in the paintings of "Water Lilies" makes people feel like they are immersed, wandering in the boundless pool of water. "Water Lilies" revealed a unique aesthetic image [1].

The Paris Orangery Art Museum (Musée de l'Orangery), near the Place de la Concorde, has a room specially designed for the impressionism painter Monet's "Water Lilies", known as the "Monet room." Eight giant water lily pictures are spread out on the curved walls of the two circular exhibition halls of the Orangery Art Museum. Under the natural light from the glass skylight, the water lily gives people an immersive feeling: Monet's water lilies make visitors experience the feeling of being surrounded in a world of water and the feeling of being surrounded by the pond and the water lily.

"Water Lilies" was one of Monet's works in his later years. Monet created this piece of work to express an immersive feeling. The main inspiration of the work comes from his garden, when he stood on the Japanese bridge of the garden, overlooking the fluctuating water surface and the water lilies on the water. From the bright colors in the sunny day to the cold quiet on a dark and windy night, some flowers bloom vibrantly in the sunshine and breeze, while others sadly wither in the wind and rain. A dreamlike vision was created to give viewers an experience of being in the garden, seeing the blue mist of the lotus pond, light changes and light shadows produced at different times, and ripples on the water surface, and hearing the birds singing in the breeze. 
As the main exhibition place of "Water Lilies", Orangery has carried out many renovations with the display of "Water Lilies" as the core theme (Figure 2). Monet even personally participated in the design of this masterpiece. The exhibition space is two oval-shaped rooms, each of the arc-shaped walls of the oval room is covered with a wide-sized "water lily", and the light comes from the skylight above. Monet's idea was to achieve a special sensory atmosphere through this design. Architect Camille Lifer completed the first renovation of the Orangery in May 1927. The construction of the exhibition hall was completely in accordance with Monet's idea. In 1966, in order to accommodate the ever-increasing exhibition, the major buildings art museum added a floor, which turned the natural sky light into electric light. This change had a devastating effect on the effect of the work and the atmosphere that was deliberately created before. In order to reproduce the artistic conception of the masters in those years, in 1999, the museum hired BLP architects to redesign the building. The new design made "Water Lily" have sky light again. Natural light once again shined on the master's work in 2006.

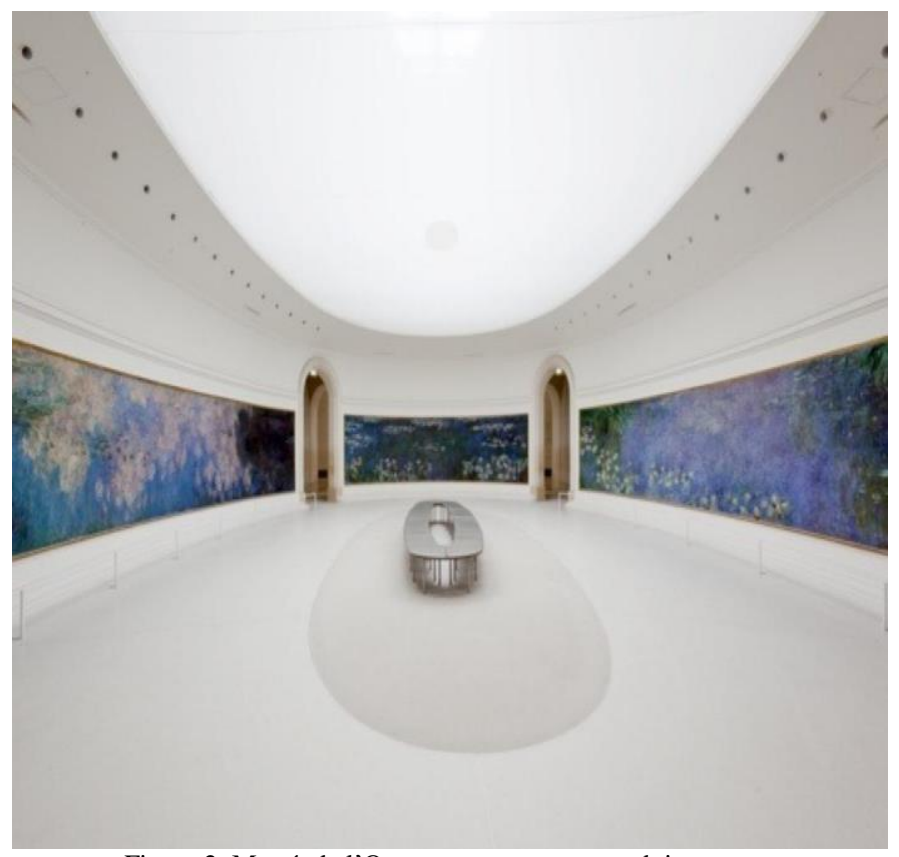

Figure 2. Musée de l’Orangery, source: www.duitang.com

The display method of the "Water Lily" exhibition hall can be regarded as an early experiment of a semi-virtual space. The curved wall fully blends the physiological characteristics of the human visual system, and the wrap-around layout creates an immersive space for the viewer. The content of the natural scene in combination with the change of light is a psychological and physiological amplification process of fixed space. With the application of new technology, the artistic expression method that Monet pursued has a new display platform.

\section{Experience Cognition of Architectural Space}

Should only a unilateral attribute such as a shape seen from the outside be focused on, or should a variety of properties be considered as a whole? In watching and feeling behavior, we not only create an objective image of the outside world, but also produce subjective feelings from our own cultural and psychological influences. The combination of this objective dimension and the subjective dimension is the source of inspiration for creating architectural works [2].

As described by Roger Scruton in Architectural Aesthetics: "In fact, we have considered that the architectural feeling is only a felling in visual aspect of the building, and even in this respect, our discussion is limited to the part of the formal feeling. But there are much more feelings to the architecture than the feelings of visual patterns and visual forms. We don't simply treat the building as a static facade. The rhythm generated by the feeling on the building may be the main effect, which may also be the object of deeper architectural research.... We can also listen to buildings, listening to its echo, listen to its whispers, listen to its quiet silence.

"All of these contributes to our overall impression. What is doubtful is that can a pure feeling felt show us all the strength of St. Peter's Basilica in Rome?... Secondly, even our visual feelings will be modified by other feelings. ...but no matter what point of view, we should not only see the color and shape, but also see such properties as warmth, volume, strength and distance" [3]. 
"A place is a whole consisting of specific things that have the nature, form, texture and color of object. The sum of these things determines a "characteristic of the environment", i.e., the nature of the place. Generally speaking. A place will all have a characteristic or "atmosphere" [4].

In the Jewish Museum in Berlin (Figure 3), Daniel Libeskind borrowed from the "Jewish story of the Holocaust" by Holocaust survivor Yaffe Eliach. "The woman glimpsed the sky through a crack in the wooden carriage as she was being transported by train from Brooklyn, New York, to the Stutthof concentration camp. A white line suddenly appeared in the sky, which she thought indicated that she would overcome the difficulty. This was the only hope." The description of such scenes was derived from the author's unique experience. The meaning was obscure but very infectious. Libeskind included it into the design and called it "the virtual space of the Holocaust." "This space was not connected to the rest of the museum. It was empty and stern, with no heating, which was not cold but not black. There was a crack in the high ceiling, with very strange angle, at which the crack couldn't be seen, but the light would penetrate in, reflect on the concrete floor and the wall." Memory reflected in the real space and then was perceived by the user [5].

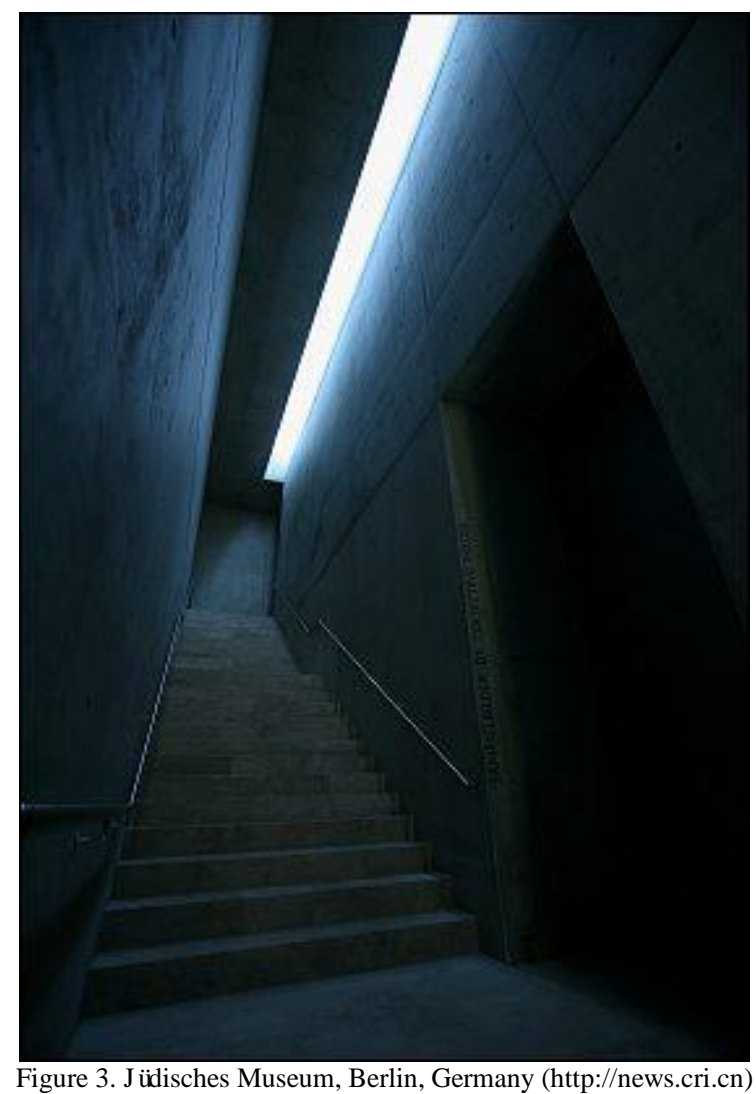

\section{The Psychological Effects of the Sensory Interface}

Willian Briken thought that psychology is the virtual reality physics. "From implements to interfaces, the extension of electronic appeared in human practice. If the implements of objects represent the extension of human sensory organs, then the interface is the electronic extension of human practice" [6].

As a boundary between objects, the interface has the meaning of information exchange in communication. The emergence of television was a great change to the traditional way of information dissemination at the time. The ancient ways of exchanging information like human behavior and language has a greater platform. The expression of language and behavior is not only the expression of sound and action, but also the product of a combination of many small changes and full information output. With the development of human beings, the emergence of words and language, and the widespread use of 2D printing art, the means of dissemination of information have been greatly developed. The receivers of the information could read the same information in different spaces and times. The spread of words and images began to affect human life. The holographic expression became a single plane image and the expression of words. Later, the emergence of other image media such as film and television developed the static single plane expression into a dynamic multi-information communication mode. However, this mode of communication still used output as the only information dissemination tool. 
As a complement to this mode of communication, the semi-virtual space enables experiencers to feel the changes of a new space created by combination of virtual and real space. This transformation can be adjusted and changed according to the designer's expression needs to realize the interaction between the experiencer and the space and achieve the purpose of communication.

For drawers of human bodies, Dali believed that it had something to do with the Freudian psychoanalysis theory: that children's natural curiosity about enclosed space drove them to open drawers, firstly to satisfy the desire to explore unknowns, and secondly to exclude the fear that unknowns may cause injuries. Freud explained that the drawer was a symbol of a woman's hidden sexual desire. In Dali's work, he also expressed his illusion of passion. "Woman Aflame" synthesized Dali's favorite image: fire, drawers, and women. Dali found that the fire was very interesting, as it was full of life and made people who saw it have a magical power. Fire also gave women sexual impulsions. Dali once explained this work with Freud's theory, which was the derivation of the curiosity of children about enclosed space. Not only did it satisfy their curiosity of what is going on, but it also removed the fear of the unknown and harmful elements. Dali added many slightly opened drawers here, suggesting that their secrets were open and were no longer afraid. Two crutches rose from the sculpture, symbolizing the combination of authority, stability, and sexual power. The visual reflection of Freud's subconscious theory became the subconscious symbols in Dali's works [7].

In Freud's view, although the subconscious was suppressed, it constantly struggled to achieve self-satisfaction. When the repressed primitive impulses or desires that do not conform to social norms were expressed in a constructive way that meets social requirements, this psychological defense mechanism was sublimation, and the form of painting, dancing, and literature, etc. were the specific manifestations of sublimation [8].

The need for immersive effects in communication is the general psychology of people. This is also a kind of obsession with watching from psychedelic psychology. According to the analysis of psychoanalysts, there is an intrinsic "scopophilia" within people. Freud regarded human scopophilia as a manifestation of sexual instinct. He believed that children's curiosity about other people's reproductive organs and physiology was the original manifestation of the scopophilia [9].

In Freud's view, scopophilia was one of the sexual instincts of human beings, and scopophilia was related to others that were viewed. "Keep the watched subject under controlled and curious gaze" to extend scopophilia by taking others as the object to be watched, and "get pleasure by looking at another as the object of sexual stimulation" [10].

This is the sexual psychological mechanism by which people get visual pleasure through watching others. This kind of pursuit of visual pleasure is particularly prominent in the communication between people. The American feminist film scholar Laura Mulvey had a famous saying: "watching itself is the source of pleasure." Studies have shown that about $65 \%$ of humans receive external information through the visual channel, $20 \%$ through the auditory channel, $10 \%$ through the tactile channel, and $2 \%$ through the taste channel. This is not only because vision is the most sensitive, direct, and laborsaving channel for information reception, but also because human beings have a kind of "watching-caused pleasure". Therefore, it is said that the most painful disability in the world is the loss of vision [11].

From a technical point of view, semi-virtual space is based on a computer system, supplemented by devices such as human-computer interaction and motion capture. The design can make the experiencer experience the atmosphere better. The basic principle is to use the high-speed data processing ability of computers to systematically integrate multiple output elements to complete the designer's design intention. It can be seen that the creation of semi-virtual space for new space is to create a new spatial experience across time and space with various data (data from physical world prototype, mixed data from physical world and artificial creation data, and purely artificial creation data). "The technical meaning of interface is used to describe the face to face intersection of two or more information sources, representing the connection between human and machine" [12].

According to Biocca, a pioneer in virtual reality technology in the United States, the basic composition of a communication interface can be defined as the interaction of physical media, communication coding, information, and user perception channels. In this interactive interface, information and perception are exchanged by input and output through the boundaries of the interface. It is expressed by a formula, that is: communication interface = (physical media, communication coding, information) + sensorimotor channel [13].

A semi-virtual space is a collection of multiple input and output devices connected to a visitor's subject sense. Experiencers enter into a new set of semi-virtual space interfaces generated by the placement of the physical space organized by the virtual space, and the experience of the presence of the experiencer is created through this multi-interface space. This experience indirectly interacts with the virtual interface through the interaction of the experiencer with the 
physical interface, so as to produce a new spatial experience. At the same time, with interactive technology such as dynamic capture, in the process of the experience, the information (visual, auditory, tactile, olfactory, taste, etc.) of each sensory channel of the visitor's body is converted into data, and the data is exchanged with the computer. These data generate new data and transform it into sensory information, which is then output through a multi-sensory output device to create a multisensory semi-virtual space.

\section{Acoustic Environment Application}

As an important part of the senses, sound also plays a significant role in the design process of the semi-virtual space. The effect of sound in different spaces is applied to the experiencer through the sound effect [14], and the interaction between the experiencer's experience and the processed sound effect will affect the experiencer's judgment. The sound part of the whole design can be embodied in the natural sound of wind, rain, thunder, water, insects, birds, and so on. Musical effects include singing songs, instrumental performances, rhythmic blows, and traditional music suiting traditional scenes. Human language includes narration for scene interpretation, dialogue simulating historical scenes, and so on [15].

Through the design of the space, the designer can apply various reflective materials such as splashing sounds on various materials including smooth surfaces and strong sound-absorbing porous materials. Through sound effects such as sound absorption, sound insulation, reflection, and echo in combination with techniques such as sound enhancement, sound simulation, and sound mixing, the live sound and playing sound are controlled to achieve the designer's sound output control [16].

The feeling of being immersive is the eternal pursuit of communication. From the earliest ancient scrawl to the long poems passed on from mouth to mouth, from the words on the walls of objects to paper and books, from silent films to VR and AR, the advancement of technology has brought more expressions of communication, following the eternal theme [17]. The feeling of being on the scene has constantly been strengthened, and the output of information has also developed from a single element to holographic expression. The sense of presence created by the piling up of words has been extended to a holographic expression that gives the viewer a stronger sense of presence.

The interactive device setting allows the experiencer to trigger the interactive device to trigger the image, sound and wind device, etc., and the logical relationship of space and place activity is output to the experiencer through the process of the triggering mechanism. For the creation of attractive spatial interactions, interactive devices are required to achieve a high-quality experience [18]. As the primary hardware, interactive devices will constitute a major part of the cost. The semivirtual space itself is characterized by the ability to enlarge the display space, and the enlarged space can achieve a larger space experience than the existing physical space under limited space conditions.

Because the semi-virtual space creates a new place and environment, it can be less interfered with by other environmental factors [19]. Designers can better use means such as sound and light in new spaces created by semi-virtual spaces. In most exhibition spaces, a large space is often used for highlighting a certain theme. The design purpose of this space is to emphasize to a large extent, but if the visitors can have similar experience through the combination with the trigger of the interactive interface, it will save ample space [20].

Just like how the best exhibition of artwork is the exhibition of original work and the best way to appreciate music is to watch live performances, the output way of scenic spots, historical sites, and excellent architectural works is the field visit [21]. The semi-virtual space can better restore the spatial experience with the assistance of holographic technology and multimedia technology. However, we must admit that the semi-virtual space interactive devices need to create a virtual space, which has a higher requirement on hardware. The application of the semi-virtual space can greatly reduce the site cost of the restoration space and achieve the goal in combination with the new technical means.

Interactive devices can provide visitors with a far more powerful feeling than receiving information just by passive watching and listening. The use of interactive modes can give visitors an all-around sensory experience. Visitors can communicate with the exhibition contents through the interactive interface or devices, which will bring visitors the experience of participation [22].

The interactive device will transmit information to the visitors through the multi-dimensional factors such as image, music, smell, and wind after the trigger to achieve the purpose of restoration and secondary creation. The enhanced visit experience provides visitors with an immersive illusion, and the intense stimulation will bring visitors a deeper impression and experience [23]. 
The interactive device makes visitors participate through physical touch or movement between humans and machines. The visitor will improve attention because of the interactive element, and the audience can get more layers of feeling through participation. For example, to set some specific instruments in the scene to simulate the behavior of production and life, the experience of cutting down trees can be felt by wielding an axe against a piling-shape device, which can convey the feeling of vibration to the experiencer. The background also makes a cutting sound. When the experiencer swings to a certain degree, the images of trees will fall. With this kind of full-sensory participation, the audience can better experience the activities happening in the exhibition scene. Through the commentary on the audience's behavior, the feeling will be magnified, and with changes of large scenes of the space, the audience can experience feelings across time and space.

\section{Conclusions}

As an important display carrier, semi-virtual space plays an important role in conveying the designer's design intent. The designer and the experiencer communicate through semi-virtual space, which appears as a platform for communication. The effect of communication depends on the designer's expression method and the experiencer's experience background. The designer and the experiencer finally complete the exhibition process through the platform of semi-virtual space.

The site creates a space atmosphere with time and space lines as the axis to guide visitors to complete the tour. The single and didactic exhibition interface has become vivid, and a more powerful performance platform is provided for the themes that designers need to express, such as geographic information, political events, natural environments, and philosophical thinking. Even the exhibition itself can be created by the designer as a work of art.

\section{References}

1. X. Wang, "The World Art Master - Monet," Jiangsu Fine Art Press, July 2010

2. J. R. Liu, "The Architect's New "Weapon" - Recognition of the Application of Virtual Reality Technology in Architectural Design," Master Thesis, Vol. 6, Southeast University, China, 2004

3. S. Roger, "Architectural Aesthetics," China Building Industry Press, Xianjue Liu Translated, Beijing, 1992

4. K. E. Blumler and J. G. Gurevitch, "Utilization of Mass Communication by the Individual," Resources and Social Practice, Vol. 31, 1974

5. D. Libeskind, "Breaking Ground: The Adventures of Life and Architecture. Bailin," Tsinghua University Press, Vol. 1, No. 31, pp. 69, 2008

6. Y. Zhang, et al., "Virtual Epistemology," Xuelin Press, Vol. 51, Shanghai, 2003

7. X. D. Jin, "Frontier Economy and the Border Economy and Culture," No. 10, pp. 105-106, 2008

8. Freud, "Interpretation of Dreams," Shanghai Sanlian Bookstore, Yanhong Zhou Translated, Shanghai, 2008

9. J. X. Peng, "Film and Television Aesthetics," Peking University Press, Vol. 333, 2002

10. L. Mulvey, "Visual Pleasure and Narrative Film," Quoted from Peng Jixiang, Film and Television Aesthetics, Peking University Press, Vol. 140, 2002

11. Y. H. Chen, "Communication: From the Interface of the Body to the Body of the Interface," Studies in Dialectics of Nature, Vol. 21, No. 3, pp. 23-27, March 2005

12. Y. Zhang, et al., "Virtual Epistemology," Xuelin Press, Vol. 51, 2003

13. Quoted from Chen Yuehua, Communication: From the Interface of the Body to the Body of the Interface. Studies in Dialectics of Nature, Vol. 21 , No. 3, pp. 23-27, March 2005

14. J. Ge and J. H. Bu, "Discussion on Acoustic Environment and Design in Urban Parks," Journal of Architecture, Vol. 9, pp. 5859,2003

15. J. Ge, "Study on the Morphological Composition and Design of Acoustic Landscape in Urban Open Space," Journal of Zhejiang University, Vol. 40, No. 9, pp. 1569-1573, 2006

16. J. Ge and X. M. Zhao, "Analysis and Design of Acoustic Landscape in Urban Landscape," Journal of Zhejiang University, Vol. 8, pp. 994-999, 2004

17. X. X. Li, "Virtual Reality Technology and Art,"Wuhan Technology University Press, pp. 28-32, 2010

18. H. Xie, "Installation Art and Architectural Environment Design," Hunan University, China, Vol. 29, 2011

19. Y. J. Xie, "Research on Artistic and Technical in Virtual Reality System," Shandong University, Jinan, China, 2009

20. L. Ma, "A Brief Analysis of the Manifestation Form of Virtual Reality Art," Art Education, Vol. 3, No. 286,2016

21. S. W. Tang, "Application of Interactive Design in Museum Display," Nanjing Art College, China, pp. 53-56, 2012

22. M. Cui, "Application and Research of Interactive Experience Design in Modern Display Space," Xi'an University of Architecture and Technology, Master Thesis, China, 2012

23. S. W. Tang, "Application of Interactive Design in Museum Display.Nanjing College of Art," Master Thesis, China, 2012 